\title{
5. Outlining a transition from cost- effective to productive rural water service improvements
}

\author{
Adam Abramson \\ Ben Gurion University of the Negev, Israel
}

\begin{abstract}
Although global trends indicate that the Millennium Development Goals for drinking water have been met, many developing countries still lag behind, including rural Sub-Saharan Africa (SSA) (United Nations Children's Fund (UNICEF)/World Health Organization(WHO) 2012). Despite a gradually emerging shift in policy from rights-based to market-based water development, and growing recognition of the importance of achieving full cost recovery of water improvements from users, market forces have remained sidelined from the rural water sector in SSA (United Nations Conference on Sustainable Development (UNCSD) 2012; United Nations (UN) 1992, 2002; Fonseca 2003). Instead, soft financing arrangements predominate, ranging from charity to, at most, user payment of operation and maintenance costs, with capital costs being met by donor funding or subsidies (Harvey 2007). As a result, the goal of minimising water costs to maximise aid effectiveness has been deeply entrenched in the sector, limiting the use of water technologies to only a few of all technologically feasible options for these areas.
\end{abstract}

According to the criteria of cost-effectiveness, most remote water interventions use the cheapest available means for providing improved water services. In many areas, this is the ubiquitous hand-pump-operated borehole - the most common water source in rural areas, with almost one billion rural users worldwide (UNICEF/WHO 2012). Hand-powered pumping is cheap, but limits the supply of water to exclusively domestic uses. Higher yielding water sources are common in many parts of Africa, suggesting that there is a widespread potential for smallscale productive or multiple-use groundwater sources (MacDonald et al. 2012). Yet higher yielding pumps, such as motorised pumps, are seldom considered, much less seen, in remote areas of SSA.

Such approaches may drastically reduce pumping costs in communities with grid electricity. For off-grid communities, solar photovoltaic (PV)-powered pumping is suitable for both productive irrigation and domestic uses, as its output aligns with the water needs of crops. It may also provide excess or 'free' electricity to off-grid communities and has minimal operation and maintenance 
costs (Burney et al. 2009). Diesel-powered pumping may be less sustainable and subject to volatile price fluctuations, but is one of the few alternatives available to off-grid communities.

Figure 1 presents a cost comparison between hand pumps and these other, higher yielding approaches for a new borehole that are typical of rural SSA: grid -, solar - and diesel-powered submersible pumps.

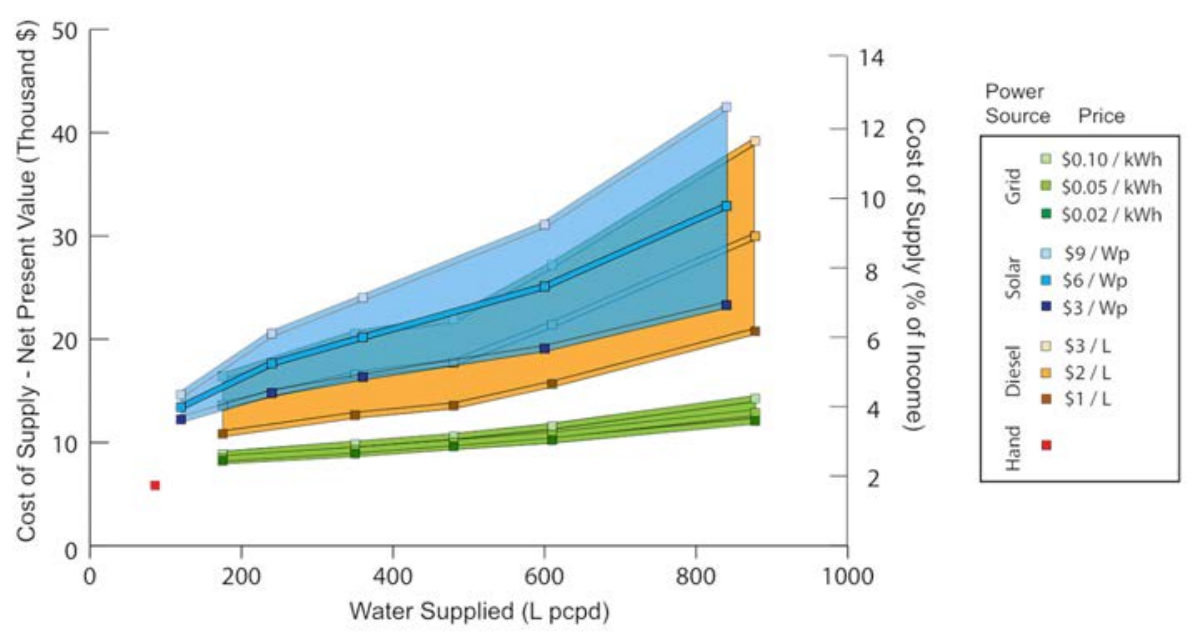

\section{Figure 1: Cost comparison of water quantity improvements by pumping method for a village of $\mathbf{2 0}$ poverty-level households}

\footnotetext{
Source: Author's research and sources referred to in the text. Cost comparison of a new community borehole across various pumping methods and yields for a village of 20 households living at the rural poverty line of $\$ 1.25$ per capita per day (pcpd). A value of 20 metres total pumping head is used as an estimate of regional average groundwater depth for SSA (MacDonald et al. 2012). A financing timeframe of 15 years is considered at a discount rate of ten per cent. A range of costs for diesel ( $\$ 1, \$ 2$ and $\$ 3$ per litre), solar PV arrays (\$3, \$6 and \$9 per Watt-peak) and grid electricity (\$.02, \$.05 and \$.10 per kilowatt hour) are compared. Grundfos WebCAPS ${ }^{\circledR}$ software was used to determine appropriate pump sizing, with local prices and meterological data for Livingstone, Zambia (Grundfos). Borehole construction was assumed to cost \$5000 (Author's fieldwork, $2009-11$ ).
}

Hand pumps are certainly the lowest cost and, for meeting minimal water supply standards, represent the most cost-effective approach. Only a small proportion (two per cent) of household income would be required to fully finance the investment (although this contribution is rarely made). The cost of transitioning from a hand pump to a higher yielding motorised pump is dependent on the source of power available, and the price of solar and diesel inputs. If grid electricity is available, there is only a marginal increase (between three to four per cent of income) in total cost across all yields investigated. If not, users would need to pay between four per cent and 12 per cent of their income for diesel-powered improvements, or between five per cent and 13 per cent for solar-powered improvements over 15 years. 
Figure 2 presents the cost of water under these alternatives.

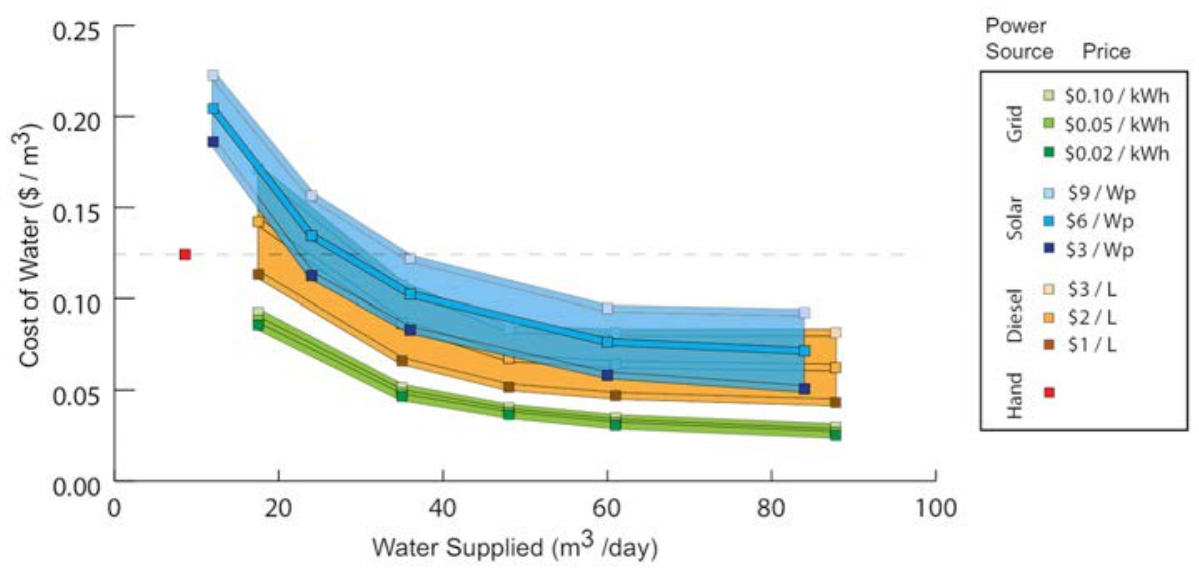

\section{Figure 2: Cost of pumped water by pumping method}

Source: Author's research. Water costs ( $\$$ /cubic metre) across the same alternatives and scenario investigated in Figure 1, with a 15-year lifetime and ten per cent discount rate. The dotted line represents the price of water at any number of hand-operated borehole replications. Almost all higher yielding alternatives provide water at a lower cost per volume than handpumps. For shallower groundwater depths than 20 metres, these trends would be more acute, and vice versa.

While handpumps provide the lowest total cost per replication, a steady decrease in marginal water costs with yield exists for alternative pumping approaches. Thus, the requirement of cost-effectiveness only holds for minimum yields (up to 20-30 cubic metres/day per borehole, or 200-300 litres pcpd for a village of 20 households). At higher yields, hand pumps are the least cost-effective alternative. In other words, the effectiveness of every dollar spent pumping water increases with the amount of water pumped. This suggests that water-related productive activities would provide increasing returns on investment, at least within these parameter ranges and assuming water is a limiting production factor.

Hand pumps are ubiquitous in rural areas primarily because low density populations have low-yield requirements for meeting domestic water service standards. Under cost-effective criteria, alternative pumping approaches are excluded since additional water only creates additional cost. But if small-scale productive water uses could be coupled to project costs, additional revenue could be generated.

To demonstrate the impact of this policy shift in a realistic, field-based context, I investigate a potential market-based 'water-for-work' program, as outlined in a previous study (Abramson et al. 2011). Under this arrangement, multiple-use water improvements that are capable of meeting both domestic and productive water needs are designed for unreached villages. Community gardens drawing 
upon these water systems are developed, and households contribute their time cultivating high-value produce, which is sold and profits directed toward financing the system. This setup removes monetary limitations and may enable market-based cost recovery of water improvements where conventional cash payments fail.

I investigate this setup in the same typical village in which a multiple-use borehole is developed, and labour in the community garden is conducted over two years (Figure 3).

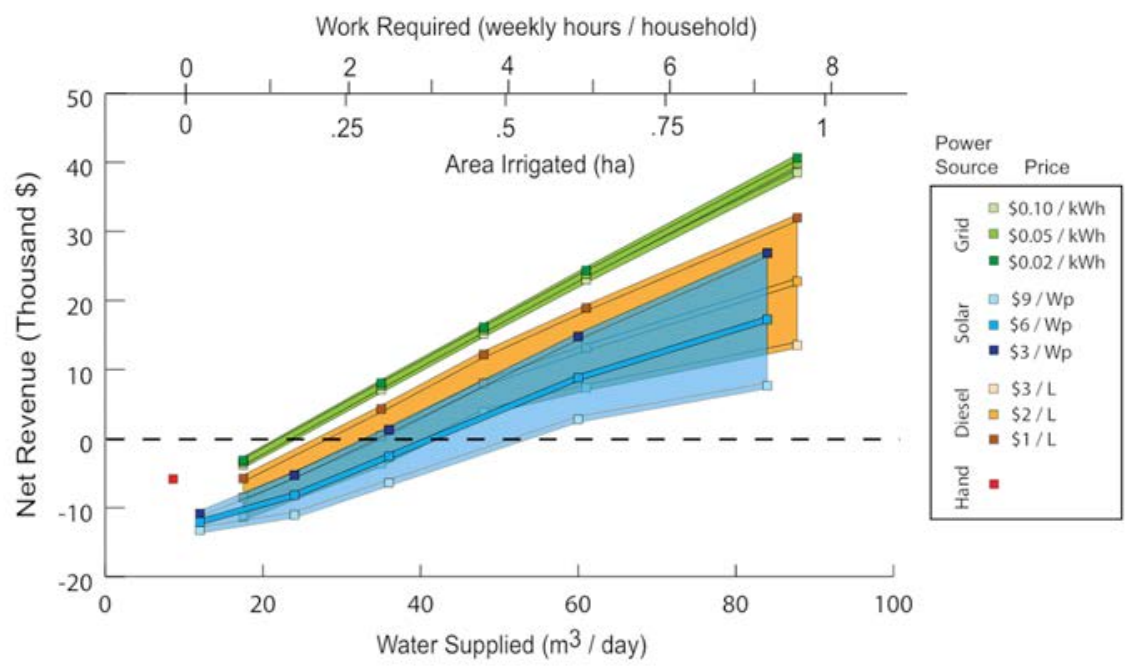

\section{Figure 3: Net revenue of hypothetical 'Water-for-Work' program coupled to various pumping methods}

Source: Author's research. Net revenue generated under a multiple-use, new community borehole and pump coupled to community drip irrigation of high-value, off-season produce. Where net revenue is above zero, full cost recovery is feasible within two years. While hand-powered pumps incur a relatively small amount of debt, the 15-year costs of higher output water supplies could be amortised with a small community work commitment in grid-connected areas, and with a larger, but still reasonable, community work investment for off-grid areas. The same scenarios described in Figure 1 are applied here, where each household is allowed 500 litres per day of domestic water. This comparison assumes that all excess water beyond that amount is used for drip irrigation of tomatoes over two seasons as part of a water-for-work approach as described by Abramson et al. (2011), who also describe the agronomic costs. A price of $\$ 1 /$ kilogram and a maximum yield of 50 tons/hectare are assumed. The Hydrus ${ }^{\circledR}$ 1-D Soil-Plant modelling software was used to model transpiration under eight millimetres of PET, groundwater salinity of 0.5 deciSiemens per metre (dS / m), and a growing season of 120 days (Hydrus). The relative yield to relative transpiration relationship for tomatoes was taken from Ben-Gal, et al., and used to determine actual tomato yield (2003). Weekly work requirements for drip irrigation are taken from Woltering et al. (2011).

Under the alternative policy of incorporating water-based revenue, optimal technology outcomes and pumping schemes are drastically changed. Because hand pumps are the lowest yielding alternative and inhibit significant productive use, they provide no return on investment. Grid-powered motorised pumps provide significant net revenue, while the costs of solar- and diesel- 
powered improvements could both be recovered fully under alternative pump outputs. For context, even these expanded outputs require labour commitments less than what has been stated and revealed from a recent field study in rural Zambia, suggesting that demand for such a program would be sufficiently high (Abramson 2012).

These results suggest that in seeking to minimise costs of rural water improvements, a strategic opportunity for rural community development is being overlooked. Certainly, other models may exist for expanding water service provision. Microfinance, for instance, is already being implemented in the rural water sector, and may provide a suitable platform for scaling this policy shift.

Adam Abramson received his $\mathrm{PhD}$ from the Blaustein Institutes for Desert Research, Zuckerberg Institute for Water Research, Ben Gurion University of the Negev. His doctoral research focused on financing rural water improvements and resulted in his thesis 'Decision support system (DSS) for assessing the feasibility of cost recovery of rural water improvements in Africa'. This article is based on his work in developing a DSS, and his field experience in rural Zambia. He thanks the Grace \& Hope Charitable Trust, United States for support for this research. He can be contacted at dr.adam.abramson@gmail.com and his website is www.outoftheground.org.

\section{References}

Abramson, A., 2012. Unpublished fieldwork results.

—, Becker, N., Garb, Y. and Lazarovitch, N., 2011. 'Willingness to pay, borrow and work for water service improvements in developing countries', Water Resources Research 47(W11512).

Ben-Gal, A., Karlberg, L., Jansen, P. and Shani, U., 2003. 'Temporal robustness of linear relationships between production and transpiration', Plant and Soil 251(2):211-18.

Burney, J., Woltering, L., Burke, M., Naylor, R. and Pasternak, D., 2009. 'Solarpowered drip irrigation enhances food security in the Sudano-Sahel', Proceedings of the National Academy of Sciences 107:1848-53.

Fonseca, C., 2003. 'Cost recovery: taking into account the poorest and systems sustainability', AWRA International Congress. Available at: http://www.irc. $\mathrm{nl} /$ page/14956.

Grundfos. WebCAPS Software. Available at: http://net.grundfos.com/Appl/ WebCAPS/custom? userid=GMAinternal. 
Harvey, P., 2007. 'Cost determination and sustainable financing for rural water services in sub-Saharan Africa', Water Policy 9:373-91.

Hydrus 1-D Modeling Software. Available at: http://www.pc-progress.com/en/ Default.aspx?hydrus-1d.

MacDonald, A.M., Bonsor, H.C., Dochartaigh, B.E.O. and Taylor, R.G., 2012. 'Quantitative maps of groundwater resources in Africa', Environmental Research Letters 7:1-7.

United Nations Children's Fund (UNICEF)/World Health Organization (WHO), 2012, 'Progress on drinking water and sanitation: 2012 update'. Available at: http://www.who.int/water_sanitation_health/publications/2012/jmp_ report/en.

United Nations (UN), 1992. 'United Nations Conference on Environment and Development', 3-14 June, Rio de Janeiro, Brazil.

_ - 2002. 'Report of the World Summit on Sustainable Development', 26 August - 4 September, Johannesburg, South Africa.

United Nations Conference on Sustainable Development (UNCSD), 2012. 'Water for the World'. Available at: http://www.un.org/en/sustainablefuture/water. shtml\#facts.

Woltering, L., Ibrahim, A., Pasternak, D. and Ndjeunga, J., 2011. 'The economics of low pressure drip irrigation and hand watering for vegetable production in the Sahel', Agricultural Water Management, 99:67-73. 
This text taken from Global Water: Issues and Insights by R. Quentin Grafton, Paul Wyrwoll, Chris White and David Allendes, published May 2014 by ANU Press, The Australian National University, Canberra, Australia. 